\title{
Total Synthesis of (-)-Colombiasin and (-)-Elisapterosin B
}<smiles>C=C(C)C=CC[C@H](C)C1C=C(C2(O)C(=O)C(C)=C2OC(C)(C)C)C(C)CC1</smiles>

A

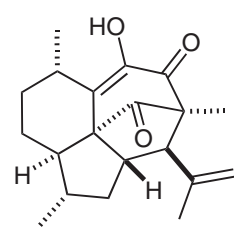

(-)-Elisapterosin B<smiles>C=C(C)/C=C/C[C@H](C)[C@H]1CC[C@@H](C)C2=C1C(=O)C(C)=C(OCC)C2=O</smiles>

C<smiles>C=C(C)/C=C/C[C@H](C)[C@H]1CC[C@@H](C)c2c(O)c(OCCC)c(C)c(O)c21</smiles>

D

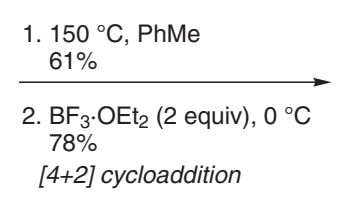

[4+2] cycloaddition

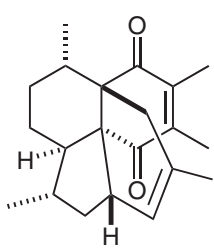

$(-)$-Colombiasin
Significance: The target molecules were isolated from the gorgonian octocoral Pseudopterogorgia elisabethae. Elisapterosin B is active against Plasmodium falciparum, the parasite associated with malaria. Two of the three stereogenic centers in $\mathbf{D}$ were derived from (-)-dihydrocarvone; the third was generated by hydroboration with $\mathrm{Ipc}_{2} \mathrm{BH}$. All remaining stereogenic centers were created by substrate-controlled processes.
Comment: A very economical synthesis of the target molecules was achieved using a sequence of pericyclic reactions. Hydroquinone $\mathbf{D}$, generated by a Moore rearrangement of the cyclobutenone A, underwent a thermal [4+2] cycloaddition to give Colombiasin A and a Lewis-acid-catalyzed [5+2] cycloaddition on treatment with $\mathrm{BF}_{3} \cdot \mathrm{OEt}_{2}$ to give Elisapterosin B. 